\title{
LA PALABRA Y EL SILENCIO
}

\section{WORD AND SILENCE}

Lorenzo Vicente Burgoa: Universidad de Murcia (España)

lorenzo.vicente@um.es

\section{CURRÍCULUM VITAE}

Doctor en Teología por la Universidad de Salamanca en 1955. Profesor de Teoría General del Conocimiento en la Universidad de Murcia (España) y autor de varios libros.

\section{RESUMEN}

Se señalan, siguiendo a los antiguos, tres ejes del lenguaje: Verbum oris, Verbum cordis, Verbum mentis. Se indica el doble sentido del proceso lingüístico. Y cómo, desde ello, se entienden mejor dos funciones del lenguaje: la imposición de nombres y la función del silencio creativo.

\section{PALABRAS CLAVE}

Verbum - Logos - Filos - Lingüística - Comunicación - Conciencia 


\section{ABSTRACT}

Is drawn, following the old, three axes of language: Verbum oris, Verbum cordis, Verbum mentis. Shows the double meaning of the linguistic process. And how, therefore, are best understood two functions of language: the naming and the role of creative silence.

\section{KEY WORDS}

Verbum - Logos - Blades - Linguistics - Communication - Awareness

\section{ÍNDICE}

1. Los tres ejes del lenguaje

2. Doble dirección

3. La imposición de los nombres

4. Silencio y Palabra

\section{TEXTO}

Es algo bien sabido que existen muchos tipos de lenguaje. Está el lenguaje interior y el exterior, el significativo y el vacío; y luego, dentro del significativo, tenemos p.e. el lenguaje declarativo o doctrinal, el inquisitivo o interrogativo, el opcional o desiderativo, el imperativo, el autoreferente, etc., etc. Ahora bien, todos esos tipos y otros similares podrían ordenarse en torno a tres ejes, que fueron ya propuestos por Agustín de Hipona y seguidos y desarrollados por los pensadores medievales. Así tenemos: 
- El Verbum oris: palabra oral, exterior.

- El Verbum cordis: palabra cordial o lenguaje del corazón

- El Verbum mentis: palabra mental, racional (logos)

\section{Los tres ejes del lenguaje}

No se trata solamente, aunque también, de una ingeniosa ordenación graduada; sino de "estados" de la Palabra en el sujeto hablante, con caracteres singulares en cada uno de tales estados.

El Verbum oris, es el lenguaje en su apariencia física; en su articulación fonética de los sonidos, articulación sintáctica de las frases y articulación semántica o de las referencias significativas en el discurso. Es el "signo" por excelencia de los otros dos tipos interiores del lenguaje, pues es el instrumento más refinado de la naturaleza evolutiva, liberada de lo físico-material, para expresar y comunicar "las internas afecciones del alma"(como decía Aristóteles). Esas otras dos secciones (o "afecciones"), las del corazón y las de la mente, cubren las dos vertientes básicas de la interioridad: la vertiente de los sentimientos y de los afectos (el verbum cordis) y la vertiente de los conocimientos (el verbum mentis). Lo que, a su vez, responde a dos polos o referentes básicos del ser real: la forma estructural o semejanza cognoscible y el fin u objetivo apetecible.

El Verbo oral o Palabra hablada cubre nuestra proyección exterior, en cuanto comunicación con otros sujetos hablantes. Y dado que sea el "signo" de la interioridad en general, es también en su uso algo, que se considera "normal" y común a todos los sujetos con posibilidad de comunicarse lingüísticamente. Siendo su carencia considerada como algo "anormal" o patológico, o al menos como una deficiencia. 
El Verbum cordis, apunta y refiere, pues, a la vertiente afectiva: opciones o deseos (desiderata), elecciones y preferencias (elicita), amores y temores (afectiones), alegrías y decepciones (passiones), laudes y recriminaciones (laudationes), imperativos y órdenes (imperata), etc. Es el lenguaje propio del poeta, que cabalga sobre la metáfora y apunta a un plano ideal, utópico; es también el lenguaje del amante y del sufriente (tada vez que amor y sufrimiento suelen ir juntos); es el lenguaje del orador y del moralista, que trata de "convencer"al oyente, más bien a través de los sentimientos, que de las ideas; es el lenguaje del gobernante y del jefe que manda, que decide lo que se ha de hacer y cómo o por quién se ha de llevar a cabo, etc. Así pues, la lírica, la retórica y la nomología (o tratado sobre la capacidad de dirigir, organizar y establecer leyes o mandatos) tienen a este tipo de lenguaje como materia prima de sus configuraciones o modulaciones.

El Verbum mentis, en fin, es la Palabra de la mente, el lenguaje interior de la consciencia. Responde, como dijimos antes, a la vertiente cognitiva, que, a su vez, se proyecta sobre el mundo de las formas: la "forma" o estructura es el medium in quo captamos las cosas reales, en cuanto distinguibles y distintas. Esa captación es el pensamiento. Y ese pensamiento es una Palabra o Verbo interior, en la cual nosotros expresamos representativamente el modo como vemos o contemplamos el mundo y a nosotros mismos en el mundo 1. Por ello, este lenguaje interior, que es el pensamiento (decimos que es como "un hablar dentro de nosotros mismos") es el lenguaje propio del pensador, del investigador, del filósofo, del científico, del maestro... El que enseña trata de reproducir en la mente del discípulo la sucesión y combinaciones de ideas, que previamente ha formado como lenguaje interior en su propia mente. "La señal de que se conoce algo es el poder enseñar a otros...", decían los antiguos; o "sólo el que sabe, puede enseñar", comunicar sabiduría.

Ahora bien, hay en nosotros como dos niveles o planos de representaciones internas: Unas son concretas, de lo inmediato o cercano, como descripción de las cosas según sus imágenes. Estas representan o "dicen" las formas y figuras determinadas, la 
cantidad o número, el orden o posición, el tamaño o la distancia, el movimiento o cambio, etc. Son las imágenes o "palabras" sensibles, que llamamos percepciones sensoriales. Todas ellas tienen su consumación en el cerebro, en alguna parte del cerebro.

Otras representaciones son más sutiles, son abstractas, esto es, no incluyen los perfiles concretos de las cosas individuales, sino sólo la estructura específica, la forma en general, lo constante o esencial, lo común o universal. Son, pues, lo que llamamos contenidos intelectuales o puramente mentales (Logos). Y todavía éstas son de diversas clases, y ello justamente como diversos tipos de lenguaje

a) Unas son las ideas o conceptos, que son como "palabras sueltas" en nuestro interior. Hay quien no puede formar una idea si no apoyándose en la palabra oral correspondiente. Aunque de suyo y absolutamente es la idea nueva lo que ha llevado a buscar y formar palabras nuevas, como sucede en la ciencia y en la técnica.

b) Otras son ideas o conceptos conexionados, articulados sintáctica o lógicamente; como son las descripciones, las definiciones de cosas, las divisiones y clasificaciones, los análisis y las síntesis, etc. Se expresan en forma de frases o proposiciones mentales (o sentencias), con la estructura básica de "S (sujeto) es (verbo) P (predicado)". Donde no por casualidad el verbo "es" (ser) constituye la cópula de ligazón entre S y P. Y cualquier frase es lógicamente reductible a una proposición con el verbo "ser". Ello indicaría que lo que queremos decir al hacer afirmaciones o negaciones, no es que así lo pensemos nosotros (salvo cuando lo digamos así) sino que así es la realidad expresada 2. Si ello es una ilusión o es un exponente de la objetividad fundamental del conocimiento, sobre ello dejemos que discutan los filósofos...

c) Finalmente, hay un lenguaje mental que es un entramado de proposiciones o sentencias, en las que de alguna manera expresamos el entramado de la realidad, sus partes, conexiones, entrecruzamientos, relaciones, etc. En este sentido es verdad que 
nuestro decir interior de alguna manera expresa el complejo entramado de lo real. Pues no sólo representa sus objetos y los hechos singulares, sino también sus relaciones, connexiones e inferencias o derivaciones.

1- Tomás de Aquino escribió: "omne intelligere in nobis, proprie loquendo est dicere: en nostros todo acto de entender el propiamente un decir"(Cuest. Disp. De Veritate, q. 4, a. $2, \mathrm{ad} 5 \mathrm{~m})$

2- L. Wittgestein escribió: "La proposición es un modelo de la realidad tal como la pensamos"(Tractatus..., 4.01)

\section{Doble dirección}

El lenguaje es un proceso o un camino, que discurre (dis-cursus) y serpentea entre dos vertientes: la interior y la exterior. Es un camino con doble dirección: una, hacia dentro de nosotros mismos; y otra hacia fuera, hacia el exterior.

a) Los contenidos lingüísticos circulan desde el exterior al interior, desde el lenguaje oído, vivo y oral, al lenguaje interno, modelando imágenes e ideas, suscitando sentimientos, determinando reacciones. Es lo que aparece en el proceso de aprendizaje. Con todo, se requiere para ello que el sujeto hablando posea unas disposiciones o habilidades innatas, esto es, capacidades para percibir el lenguaje externo, de gestos o sonidos, de modo significativo. Es decir, de modo que el signo lingüístico constituya un eficaz vehículo o trasunto del objeto significado. Llamamos "consciencia" a esta disposición interna previa, que nos permite "darnos cuenta", percibir , tanto las impresiones de los objetos, como los signos lingüísticos. Mas para la percepción de los signos lingüísticos se requiere un nivel superiro de cosnciencia, pues aparte de poder percibir el signo en su realidad física (lenguaje oral) como 
impresión sensible, se ha de poder descifrar o descodificar el signo como tal: esto es, se ha de poder reconocer la distinción entre signo o significación y significado o contenido, así como la relación o referencia del signo al significado. Esta habilidad o competencia ha de ser tanto mayor cuanto la relación entre signo y significado sea más arbitraria o convencional, menos natural. Así pues, la competencia radical o consciencia es innata y anterior; la competencia funcional $u$ operativa del lenguaje es adquirida y perfectible por aprendizaje.

No es, pues, casual sino una consecuencia lógica, el que a niveles superiores de cosnciencia encontremos en la escala de los seres vivos, niveles superiores de simbolismo y de lenguaje liberado de lo físico. Así, cuando el lenguaje se compone de símbolos o signos abstractos, de trasuntos metafóricos, de sentidos irónicos o de expresiones metasensibles, ello no indica necesariamente un sinsentido, sino que comporta estructuras superiores y más refinadas de consciencia (= cum+scientia).

b) Lo anterior está indicando a la par, que en este proceso se da también un sentido inverso, de dentro hacia afuera; desde los lenguajes internos, mental o cordial, al lenguaje oral.

Ello aparece de modo notable en el hecho de la invención o imposición de los nombres a las cosas. Aunque también en el modo como el pensamiento creativo requiere del reposo y del silencio.

\section{La imposición de los nombres}

Ya los medievales llamaron la atención sobre que se ha de distinguir entre: el nombre, que se pone a una cosa y la cosa misma a la que se pone un nombre 3. Esta noble operación de "poner un nombre" parece algo reservado al "animal capaz de la palabra articulada", que es el hombre 4. 
Ahora bien, hay dos modos principalmente de poner nombres a las cosas nuevas o de cambiarlos: Así para nombrar algo nuevo, como una nueva especie de animales o plantas o un nuevo aparato de la técnica, se recurre a los patrones establecidos, como son las raíces etimológicas de una lengua dada; ya sean propias, como en las lenguas más primitivas, ya sean derivadas, como en las lenguas románicas, derivadas del latín y del griego.

Pero hay otro modo más radical o más "natural" por así decirlo y que consiste en que los nombres se pusieron o impusieron atendiendo a alguna cualidad sobresaliente o más impactante en las cosas. Esa cualidad puede ser, unas veces una cualidad sónica o fonética; lo que da lugar al llamado "lenguaje onomatopéyico", en que la voz misma en su expresión fónica remite a lo significado (p.e. en la palabra "silbido"). Lo más normal, sin embargo, es alguna cualidad físico-sensible, que impacta al observador primero. Así p.e. si aceptamos la etimología de "hombre" (en latín homo), que provendría de humus, y significa "tierra". Lo que da origen el nombre es el impacto de la muerte, por la que el hombre viene a ser o hacerse "humus", tierra. Hay muchos ejemplos, que podrían aducirse. Baste ahora indicar que los nombre o "motes", que se ponían en los pueblos a ciertas personas y por los que eran mejor conocidas, solían referirse a alguna cualidad o defecto sobresaliente de la misma: así p.e. "el cojo", "el manco", "el oncebrutos", o simplemente "león”, "lobo”, etc.; y hasta muchos apellidos reales, como "carpintero", "herrero", por el oficio, etc., etc. Es, pues, lo que más nos impresiona a primera vista, lo que ha dado lugar al nombre que se puso a ciertas cosas. Y dado que lo que primero que conocemos de cada cosa es lo externo, lo superficial o más aparente (fenómeno), y siempre alguna cualidad física o material, ello es la fuente del significado primario de muchos nombres. Así p.e. "exercitus", vendría de "exercere", esto es, del ejercicio y la disciplina a que está sometida en su conjunto la tropa o ejército militar. Pero por lo mismo se dice también "ejercicio mental" o "ejercicios espirituales", etc., en cuanto implican trabajo y disciplina interior. 
Y esa diferencia entre el significante y el significado explica también el desplazamiento semántico o cambio de significado de las palabras en su uso a través del tiempo y de las diversas situaciones culturales. La misma palabra con un significa físico y de tipo agrícola, pasa luego a significar algo similar, pero diferente, al pasar desde la cultura del campo a la cultura de la ciudad. Así p.e. la palabra "persona" parece provenir de "per-sonare" o hablar a través de una máscara, como hacían los actores del teatro griego y latino. Luego significa al sujeto mismo, que lleva la máscara, el "personaje".

Mas siempre resulta interesante poder conocer el origen etimológico o significación primaria de una palabra, ya que en ello hay siempre como un poso semántico, que nos lleva a detectar alguna cualidad sobresaliente de la misma cosa significada. A ello lo he denominado "experiencia semántica" 5 , que consiste justamente en que en el lenguaje se halla frecuentemente un trasfondo semántico, significativo, que remite a una experiencia primitiva, inmediata y objetiva, respecto del objeto nombrado.

3- $\mathrm{O}$ en las expresiones latinas usadas por los medievales: id a quo nomen imponitur /id cui nomen imponitur.

4- En la Biblia se dice que ante Adán desfilaron todos los animales del campo y las aves del cielo, para que él les pusiera un nombre (Cf. Génesis, 2, 19).

5- Cf. nuestro artículo "La "esencia" del conocimiento desde la experiencia semántica", en SAPIENTIA (Argentina), 1999 (54) 481-498 


\section{Silencio y Palabra}

Otro momento de ese movimiento del lenguaje, desde dentro hacia afuera lo encontramos en la necesidad de combinar la palabra con el silencio. Es una articulación más psicológica que lógica o gramatical. Pero no menos importante y necesaria para el pensamiento creativo, el de los investigadores, de los pensadores y de los artistas.

Para ello, tomo pie de uno de los consejos que un sabio medieval daba a un discípulo, en orden a la adquisición del conocimiento y de la sabiduría: “Te aconsejo que seas tardo en hablar y largo en callar, que no tengas prisa por ir a los lugares de cotorreo y de conversaciones vanas e inútiles"

Es decir, en sentido moderno, no seas excesivamente ansioso de escuchar novedades, pues esto dispersa la atención, debilita el ánimo y, sobre todo, la excesiva abundancia de información, cuando no hay tiempo de digerirla, produce hartura e indigestión. Esto es, cuando se llena la mente con mucha información, esto absorbe las fuerzas de la mente y se va todo en memoria, quitando tiempo y fuerza para el ejercicio de la reflexión. Porque el conocimiento no consiste en saber muchas cosas, sino en conocerlas bien, esto es, en poder juzgar de ellas, valorarlas debidamente, con claridad y con la mayor certeza posible. Y todo esto requiere tiempo de reflexión, de contrastación y de juicio. La abundancia de temas impide detenerse en cada uno para darles vueltas en la mente, para asimilarlos satisfactoriamente. Sucede como cuando alguien asume alimentos en exceso, que no puede digerir y le producen hartura y a veces hasta hastío. O también, como suele decirse, "la abundancia de árboles impide ver el bosque". Esto es, cuando entramos dentro de un bosque, ello nos impide ver el conjunto, y hasta nuestra situación misma dentro del bosque; de modo que nos sentimos desorientados y perdidos 6. Así también, la superabundancia de palabras o de informaciones con frecuencia nos impide ver lo esencial, el conjunto sistemático, la estructura de la cosa o del problema a estudiar. 
No se trata, pues, de excluir el diálogo y la discusión provechosa, sino de dejar de lado la vana charlatanería; y buscar el silencio interior, en el que maduran las ideas y los grandes proyectos. Es verdad aquello de "temo al lector de un solo libro". Mas frente a ello se ha de decir también: "temo al lector de inumerables libros", sin asimilarlos, sin un minuto de reposo, de alto en el camino, de silencio fecundo. Por ello, el investigador, el poeta y el maestro necesitan retirarse periódicamente a un ambiente de silencio. Es el silencio creativo, fecundo; que no es carencia absoluta de palabra, sino oído y escucha de la palabra interior, la de la mente o del corazón.

6- Cf. nuestra obra: Los caminos del trabajo intelectual. Anexo, pp.197- 198 (Ed. Netbiblo, 2008). 